\title{
Extended Dating Platelets
}

National Cancer Institute

\section{Source}

National Cancer Institute. Extended Dating Platelets. NCI Thesaurus. Code C133349.

Platelets that have been tested for bacteria using an FDA-cleared rapid bacterial detection device labeled as a safety measure, following testing with a growth-based quality control test cleared by the FDA for platelet components, that can support extending the expiration date of platelets past 5 days. 